$\mathrm{DE}$

M E D I C I N A

T R O P I C A L

$\mathrm{DE}$

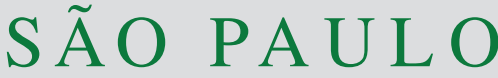

JOURNAL OF THE SÃO PAULO INSTITUTE OF TROPICAL MEDICINE

${ }^{1}$ Hospital Municipal, Santarém, Pará, Brazil

2Universidade de São Paulo, Faculdade de Medicina, São Paulo, São Paulo, Brazil

3Universidade de São Paulo, Hospital das Clínicas, Laboratório de Investigação Médica em Imunologia (LIM 48), São Paulo, São Paulo, Brazil

Correspondence to: Helena Rangel Esper Universidade de São Paulo, Hospital das Clínicas, Laboratório de Investigação Médica em Imunologia (LIM 48), Av. Dr. Enéas de Carvalho Aguiar, 470, Prédio II, CEP 05403-907, São Paulo, SP, Brazil

E-mail: helena_liv@yahoo.com.br

Received: 30 January 2019

Accepted: 2 April 2019

\section{Fatal evolution of acute Chagas disease in a child from Northern Brazil: factors that determine poor prognosis}

\author{
Helena Rangel Esper ${ }^{1,2}$, Vera Lucia Teixeira de Freitas ${ }^{\circledR 2}$, João Guilherme \\ Pontes Lima Assy ${ }^{1,2}$, Erika Yoshie Shimoda ${ }^{3}$, Olivia Campos Pinheiro \\ Berreta $^{1,2}$, Marta Heloisa Lopes ${ }^{2,3}$, Francisco Oscar Siqueira França ${ }^{2,3}$
}

\section{ABSTRACT}

Trypanosoma cruzi is the causative agent of Chagas disease. Nowadays, the transmission in Brazil occurs mainly by oral ingestion of contaminated food that has been associated with more severe clinical manifestations. We report a case of Acute Chagas disease caused by oral transmission in a child from Northern Brazil. In the hospital admission, physical examination showed tachycardia, hepatomegaly, bipalpebral edema and anasarca. Trypanosoma cruzi trypomastigotes were found in microscopy during blood cell count. Twenty-three days before hospitalization, the child had ingested the "bacaba palm fruit's wine". Even with the appropriate diagnosis and starting of treatment, she did not survive. Quantitative analysis of Trypanosoma cruzi DNA in a blood sample resulted in $54,053.42$ parasite equivalents $/ \mathrm{mL}$ and the DTU TcIV was identified. The outcome may have been determined by several factors, including the delay to seek a medical service beyond the high parasitemia, detected by qPCR. DTU TcIV could also have influenced the natural history of the disease.

KEYWORDS: Acute Chagas disease. Trypanosoma cruzi. qPCR. Bacaba palm fruit. Children.

\section{INTRODUCTION}

Chagas disease (CD) is a vector borne disease caused by Trypanosoma cruzi (T. cruzi). The clinical course of Chagas disease is usually divided into an acute phase and a chronic phase. The acute phase immediately follows infection. In the past, the disease was transmitted mostly by infected feces deposited during the vector blood meal. In addition to vector-borne transmission, $T$. cruzi may be transmitted through blood transfusion, organ solid and stem cels transplantation. In spite of advances in vector and transfusion control programs especially from Intergovernmental initiatives triggered in the 1990s. Chagas disease still remains an important public health problem due to congenital transmission and ingestion of contaminated food ${ }^{1}$. Acute Chagas disease (ACD) is characterized by an acute febrile syndrome associated with nonspecific signs and symptoms similar to other tropical diseases such as malaria, visceral leishmaniasis and typhoid fever ${ }^{2}$. If undetected and untreated, its mortality can reach $10 \%$ of the cases ${ }^{3}$. Chagas disease (CD) is a neglected disease and the measures necessary for its prevention, diagnosis and treatment are far from ideal. Its prevalence is unclear due to underreporting and the spatial heterogeneity of the zoonotic cycle 4 . In Brazil, most ACD cases occur in the Amazon Region whose vast area, with immense biodiversity, limits surveillance and vector control. Besides, the access to health services is precarious. 
In this region, the main source of infection is the oral ingestion of contaminated food, such as açaí (Euterpe oleracea) or bacaba palm fruit (Oenocarpus bacaba). Recently, an increase in the number of cases has been recorded despite the initiatives of artisanal products quality control $^{5}$. Detection of acute phase infections is relatively uncommon due to the nonspecific clinical symptoms observed in most infected patients. Frequently, only the more severely affected patients are diagnosed in this phase $^{6}$. Direct examination of stained thick blood smears are widely used in the Brazilian Amazon region due to the practicality, low cost and availability ${ }^{7}$. Currently, access to PCR for detection of acute phase infections or reactivations is limited and, in general, not available in the areas where oral transmission is more frequent. The Faculdade de Medicina of the Universidade de Sao Paulo, SP, maintain in the city of Santarem, Para State, Brazil, the Nucleus of Tropical Medicine (NUMETROP), with a small team of medical doctors specialized in tropical diseases.

We report an ACD case that occurred in the municipality of Santarem, Para State, Brazil, in a 22 months-old infant, after the oral ingestion of bacaba palm fruit's wine. Correct but late diagnosis and treatment were insufficient to save her life, indicating the need for better management and methods that could help clinicians. Another eight cases of ACD were diagnosed in the same riverside community.

\section{CASE REPORT}

NUMETROP infectious physicians of the Hospital Municipal de Santarem admitted a 22 female monthsold infant, in April 2016, in a fair general condition, with bipalpebral edema and anasarca. She was from the Riverside community of Marimarituba, municipality of Santarem, Para State, far from Santarem downtown eight hours by boat. The parents refered she has had fever, vomiting, diarrhea and upper abdominal pain thirteen days before the hospital admission (Figure 1). Homogeneous central rash, heart rate of $112 \mathrm{bpm}$ and liver at $2 \mathrm{~cm}$ below the costal margin were observed in the physical examination.
Admission exams results: Hemoglobin $10.2 \mathrm{~g} / \mathrm{dL}$, hematocrit $28.4 \%, 7,800$ leukocytes $/ \mathrm{mm}^{3}$, 4,602 lymphocytes $/ \mathrm{mm}^{3}$, platelets $102,000 / \mathrm{mm}^{3}$, positive blood smear with visualization of T. cruzi trypomastigotes. When asked, the parents reported that twenty-three days before hospitalization, the child had ingested the "bacaba palm fruit's wine", corresponding to Day 0 in Figure 1. She was the first patient detected in an outbreak with more eight infected individuals detected. Additional exams showed AST 83 U/L, ALT 55 U/L. Normal Chest X-ray. Electrocardiogram: inversion of the T wave in V1-V3. On day 24 , treatment was initiated with orally administrated Benznidazole (10 mg/kg/day, three times a day), and no side effects were noticed. She was discharged asymptomatic with negative blood smear on day 10 of Benznidazole, due to social reasons.

Her parents were oriented to return if there was worsening of the clinical picture. A 60-day treatment was prescribed, but the patient suddenly died three days later (Figure 1). Necropsy was not available. The indirect immunofluorescence (IF) tests, which were performed in the LACEN (Central Laboratory of Public Health of Para), were positive for anti-T.cruzi IgG antibodies (titer 1/160) and for IgM antibodies (titer 1/80).

Other specific tests for the diagnosis of ACD were collected after 5 days of Benznidazole and carried out in a research laboratory at the Faculdade de Medicina of the Universidade de Sao Paulo, that supports NUMETROP, after the the parents' authorization. The study was approved by the Research Ethics Committee of Faculdade de Medicina of the Universidade de Sao Paulo, process $\mathrm{N}^{\circ} 2695.519$.

The Laboratory of Medical Research in Immunology of the Hospital das Clinicas of the Universidade de Sao Paulo, that supports NUMETROP, carried out in house molecular tests.

\section{Quantitative PCR}

Quantitative PCR (qPCR) for T. cruzi detection was performed following previously described methodology ${ }^{8}$.

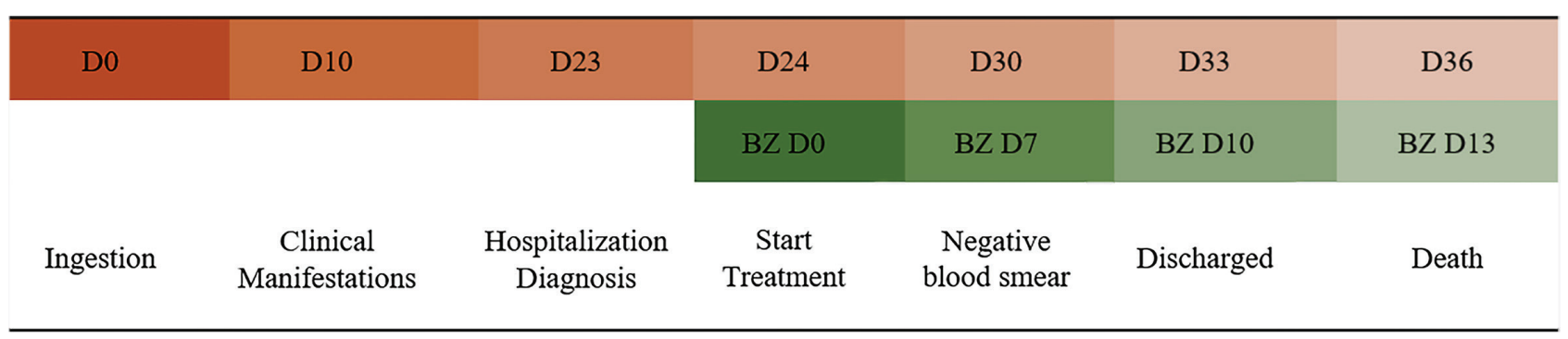

Figure 1 - Evolution of the patient from the ingestion of "bacaba palm fruit's wine" until the fatal outcome. 
T. cruzi was typed using two different parasite genomic sequences.

\section{$24 \mathrm{~S} \alpha$ ribosomal (rRNA) gene D7 domain}

The hemi-nested PCR was performed as previously described $^{9}$ with modifications: D75 and D76 primers were used in first round and D71 and D72 primers were used in the second round. Amplifications were performed in a GenePro Thermal Cycler (Hangzhou Bioer Technology Co., Ltd., China), as follows: first round, touchdown hold (95 ${ }^{\circ} \mathrm{C}$ for $\left.3 \mathrm{~min}\right) ; 6$ cycles $\left(94{ }^{\circ} \mathrm{C}\right.$ for $60 \mathrm{~s} ; 64^{\circ} \mathrm{C}$ for $60 \mathrm{~s}$; $72{ }^{\circ} \mathrm{C}$ for $60 \mathrm{~s}$; reducing the annealing temperature by $2{ }^{\circ} \mathrm{C}$ each 2 cycles); 29 cycles ( $94{ }^{\circ} \mathrm{C}$ for $60 \mathrm{~s} ; 58{ }^{\circ} \mathrm{C}$ for 60 's; $72{ }^{\circ} \mathrm{C}$ for $\left.60 \mathrm{~s}\right)$. The second round parameters were: $94{ }^{\circ} \mathrm{C}$ for $3 \mathrm{~min} ; 3$ cycles $\left(94^{\circ} \mathrm{C}\right.$ for $30 \mathrm{~s}, 60{ }^{\circ} \mathrm{C}$ for $30 \mathrm{~s}, 72^{\circ} \mathrm{C}$ for $30 \mathrm{~s}) ; 3$ cycles $\left(94^{\circ} \mathrm{C}\right.$ for $30 \mathrm{~s}, 57^{\circ} \mathrm{C}$ for $30 \mathrm{~s}, 72^{\circ} \mathrm{C}$ for $30 \mathrm{~s}) ; 20$ cycles $\left(94^{\circ} \mathrm{C}\right.$ for $30 \mathrm{~s}, 55^{\circ} \mathrm{C}$ for $30 \mathrm{~s}, 72^{\circ} \mathrm{C}$ for $30 \mathrm{~s})$. Amplicons of 110-bp are characteristic of TcI/TcIII DTU; 125-bp of TcII/TcVI; $110+125$-bp of TcV and 120 or 130 of TcVI.

\section{Spliced leader genes intergenic region (mini-exon gene)}

DNA was amplified according to the previously described multiplex protocol ${ }^{10}$ : Three oligonucleotides, derived from a hypervariable region of the T. cruzi miniexon repeat and an oligonucleotide from a specific region of the $T$. rangeli nontranscribed spacer were used as upstream primers. A common oligonucleotide, designed in the most conserved part of the miniexon, was used as the downstream primer. Amplicons of 150-bp are characteristic of TcIII/TcIV DTU; 200-bp of TcI and 250-bp of TcII; TcV as well as TcVI and $T$. rangeli generated an amplicon of $100 \mathrm{pb}$.

Amplified products were visualized by means of a capillary gel electrophoresis apparatus (GelBot, Loccus
Biotecnologia, Brazil). A high resolution cartridge S1 kit was applied (Loccus Biotecnologia, Brazil) and data were analyzed by means of the software Q-Analyzer.

Trypanosoma cruzi, and Trypanosoma rangeli reference strains were used as markers of the six DTUs (Table 1).

\section{DISCUSSION}

In this case report, it is important to highlight the variables that may have influenced the fatal outcome. Death among young people is described in ACD outbreaks ${ }^{11-13}$. Beyond the young age, her remarkable symptomatology, characterized by the presence of multiple clinical manifestations, compatible with the simultaneous involvement of several organs and systems, could be related to the fatality. This child presented fever, tachycardia, gastrointestinal manifestations (vomiting, diarrhea, hepatomegaly and upper abdominal pain), skin rash, anasarca whereas ACD is usually oligosymptomatic or asymptomatic ${ }^{2}$. Oral transmission of $T$. cruzi has been associated with more severe clinical outcome ${ }^{14}$ when the usual cause of death is frequently an acute myocarditis. However, fatal evolution due to stroke and upper gastrointestinal bleeding has also been described. Treatment was not initiated until 15 days after the beginning of the clinical manifestations. This delay may have contributed to the slower therapeutic response, given the extent of the illness ${ }^{15}$.

In addition, her laboratorial parameters showed low platelets and altered liver enzymes in parallel with the very high parasitemia. Taken together, all these factors contributed to the fatal evolution ${ }^{16}$. In the fatal case reported herein, the parasite load was extremely high (54,053.42 parasite equivalents/mL) by qPCR; this result is corroborated by a clinical study in which parasitic loads in ACD samples were higher than in chronic CD cases, reaching concentrations of up to $8 \log _{10}$ parasite equivalents/10 $\mathrm{mL}^{17}$. However, parasites were not detected

Table 1 - Description of Trypanosoma cruzi and Trypanosoma rangeli reference strains used in this study and the respective gene sequences GenBank accession numbers.

\begin{tabular}{|c|c|c|c|c|c|c|}
\hline \multirow[b]{2}{*}{ Species } & \multirow[b]{2}{*}{ DTU } & \multirow[b]{2}{*}{ Sample ID } & \multirow[b]{2}{*}{ Host species } & \multicolumn{3}{|c|}{ GeneBank accession number } \\
\hline & & & & SSUrDNA & $\begin{array}{c}\text { Cytochrome } \\
\text { oxidase subunit II }\end{array}$ & $\begin{array}{c}\text { Cathepsin L-like } \\
\text { protein }\end{array}$ \\
\hline \multirow{6}{*}{ T. cruzi } & $\mathrm{Tcl}$ & $\mathrm{JR}$ cl4 & H. sapiens & & HQ604893.1 & \\
\hline & Tcll & $\mathrm{Y}$ & H. sapiens & AF301912 & & \\
\hline & Tclll & MT3663 & H. sapiens & AF303060 & & \\
\hline & TclV & JJ & H. sapiens & AY491761 & & \\
\hline & $\mathrm{TcV}$ & Bertha & H. sapiens & FJ555614 & & \\
\hline & TcVI & CL Brener & T. infestans & AF245383 & & \\
\hline T. rangeli & & Tra1719 & A. planirostris & & & JF421351 \\
\hline
\end{tabular}


by blood smear examination performed on the seventh day of Benznidazole treatment.

The genetic diversity of the parasite can probably have influenced the natural history of the disease, the diagnosis and the treatment of $\mathrm{ACD}^{18}$. T. cruzi specific DTU TcIV was observed and is shown in Figures 2A and 2B. In the Amazon Basin, DTU TcI and IV are the usual T. cruzi DTUs found in isolates ${ }^{19}$. In experimental studies, TcIV showed higher virulence and fatality rate in shorter periods of time when compared to $\mathrm{TcI}^{20}$. The different behaviors of each DTU can possibly be associated with the severity of infections, and it is possible that in humans, TcIV may also be more virulent and associated with the fatal evolution observed in this child.

Nevertheless, the frequency of T. cruzi DTUs during outbreaks in the Amazon region is currently unknown. As a large amount of T. cruzi DNA is required for the DTU typing, methods such as hemoculture and xenodiagnosis are often used to increase the number of available parasites before DTU typing, which may select a faster multiplying DTU, masking the DTU typing result. In this study, the DTU typing was directly performed from the patient's blood, eliminating this "masking effect".
In a retrospective study carried out from 2009 to 2013, it was shown that the number of cases and the lethality of ACD represents a serious public health problem in Brazil $^{12}$ and from an economical point of view it is worth paying attention and investing on fighting Chagas disease. It is also important that research laboratories contribute to the diagnosis and to increase information on the parasite complexity, which can potentially improve the quality of medical care, avoiding outcomes as unfavorable as the one described in this report.

\section{FUNDING}

No funding was secured for this study.

\section{CONFLICT OF INTERESTS}

The authors have no conflict of interests to disclose.

\section{AUTHORS' CONTRIBUTIONS}

Helena Rangel Esper and Vera Lucia Teixeira de Freitas conceptualized and designed the study, drafted the initial
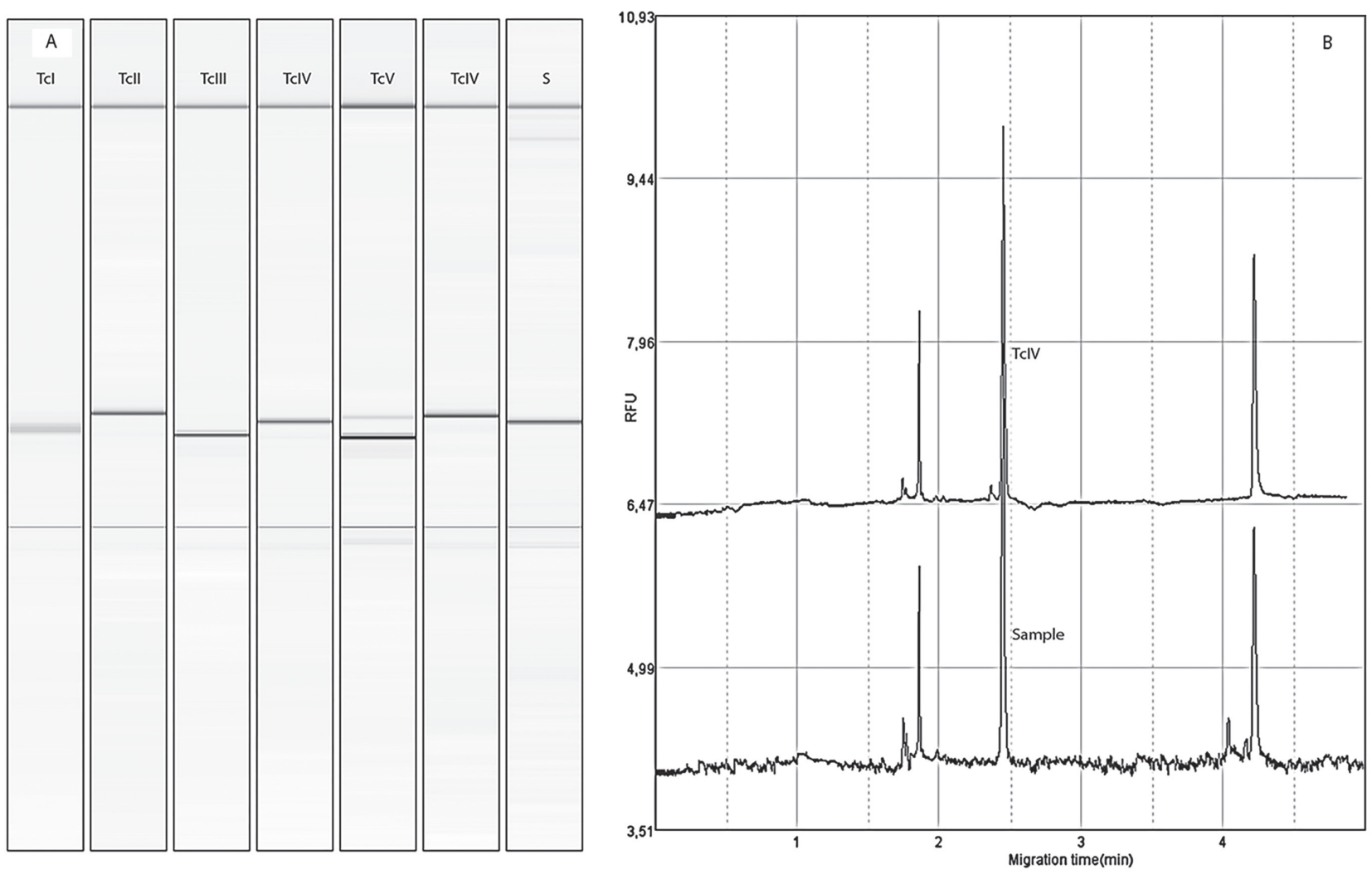

Figure 2 - Representative electrophoretic pattern of 24S $\alpha$ region of T. cruzi. A) Lanes I-VI: reference strains Tcl (JR cl4), 110 bp; Tcll (Y), 125 bp; TcIll (MT3663), 110 bp; TcIV (JJ), 120 bp; TcV (Bertha), 125 and 110 bp and TcVI (CL-Brener), 125 bp; Lane S, pattern of the 120-bp amplication product from the $24 \mathrm{~S} \alpha$ region from a human blood sample; B) The eletropherogram shows the relative fluorescent unit (RFU) of the amplified fragment: $24 \mathrm{~S} \alpha$ of the reference strain TcIV (JJ) and the pattern of $24 \mathrm{~S} \alpha$ region (120 bp) amplification product from a human blood sample. 
manuscript and reviewed the manuscript; João Guilherme Pontes Lima Assy and Olivia Campos Pinheiro Berreta designed the data collection instruments, collected data, carried out the initial analyses and reviewed the manuscript; Erika Yoshie Shimoda carried out the molecular assays, the initial analyses and reviewed the manuscript; Marta Heloisa Lopes and Francisco Oscar Siqueira França conceptualized and designed the study, coordinated and supervised data collection, have written and critically reviewed the manuscript. All authors approved the final manuscript as submitted and agree to be accountable for all aspects of the study.

\section{REFERENCES}

1. Dias JC, Ramos Jr AN, Gontijo ED, Luquetti A, Shikanai-Yasuda MA, Coura JR, et al. $2^{\text {nd }}$ Brazilian Consensus on Chagas' Disease, 2015. Rev Soc Bras Med Trop 2016;49 Suppl 1:3-60.

2. Shikanai-Yasuda MA, Carvalho NB. Oral transmission of Chagas disease. Clin Infect Dis. 2012;54:845-52.

3. World Health Organization. Control of Chagas disease: second report of the WHO expert committee. Geneva: WHO; 2002.

4. Stanaway JD, Roth G. The burden of Chagas disease: estimates and challenges. Glob Heart. 2015;10:139-44.

5. Santos VR, Meis J, Savino W, Andrade JA, Vieira JR, Coura JR, et al. Acute Chagas disease in the state of Pará, Amazon region: is it increasing? Mem Inst Oswaldo Cruz. 2018;113:e170298.

6. Nóbrega AA, Garcia MH, Tatto E, Obara MT, Costa E, Sobel J, Araujo WN. Oral transmission of Chagas disease by consumption of açaí palm fruit, Brazil. Emerg Infect Dis. 2009;15:653-5.

7. Brasil. Ministério da Saúde. Secretaria de Vigilância em Saúde. Coordenação-Geral de Desenvolvimento da Epidemiologia em Serviços. Guia de vigilância em saúde. $2^{\text {a }}$ ed. Brasília: Ministério da Saúde; 2017. [cited 2019 Apr 2]. Avaliable from: http://portalarquivos.saude.gov.br/images/pdf/2017/ outubro/06/Volume-Unico-2017.pdf

8. de Freitas VL, da Silva SC, Sartori AM, Bezerra RC, Westphalen EV, Molina TD, et al. Real-time PCR in HIV/Trypanosoma cruzi coinfection with and without Chagas disease reactivation: association with HIV viral load and CD4+ level. PLoS Negl Trop Dis. 2011;5:e1277

9. Fernandes O, Santos SS, Cupolillo E, Mendonça B, Derre R, Junqueira AC, et al. A mini-exon multiplex polymerase chain reaction to distinguish the major groups of Trypanosoma cruzi and T. rangeli in the Brazilian Amazon. Trans R Soc Trop Med Hyg. 2001;95:97-9.
10. Aliaga C, Brenière SF, Barnabé C. Further interest of miniexon multiplex PCR for a rapid typing of Trypanosoma cruzi DTU groups. Infect Genet Evol. 2011;11:1155-8.

11. Brandão E, Romero S, da Silva MA, Santos FL. Neglected tropical diseases in Brazilian children and adolescents: data analysis from 2009 to 2013. Infect Dis Poverty. 2017;6:154

12. Bastos CJ, Aras R, Mota G, Reis F, Dias JP, de Jesus RS, et al. Clinical outcomes of thirteen patients with acute Chagas disease acquired through oral transmission from two urban outbreaks in northeastern Brazil. PLoS Negl Trop Dis. 2010:4:e711.

13. Alarcón de Noya B, Díaz-Bello Z, Colmenares C, Ruiz-Guevara R, Maurello L, Zavala-Jaspes R, et al. Large urban outbreak of orally acquired acute Chagas disease at a school in Caracas, Venezuela. J Infect Dis. 2010;201:1308-15

14. Barreto-de-Albuquerque J, Silva-dos-Santos D, Pérez AR, Berbert LR, de Santana-van-Vliet E, Farias-de-Oliveira DA, et al. Trypanosoma cruzi infection through the oral route promotes a severe infection in mice: new disease form from an old infection? PLoS Negl Trop Dis. 2015;9:e0003849.

15. Organização Pan-Americana da Saúde. Doença de Chagas: guia para vigilância, prevenção, controle e manejo clínico da doença de Chagas aguda transmitida por alimentos. Rio de Janeiro: OPAS; 2009. [cited 2018 Oct 10]. Avaliable from: http://bvsms. saude.gov.br/bvs/publicacoes/guia_vigilancia_prevencao_ doenca_chagas.pdf

16. Pinto AY, Valente SA, Valente VC, Ferreira Jr AG, Coura JR. Fase aguda da doença de Chagas na Amazônia brasileira: estudo de 233 casos no Pará, Amapá e Maranhão observados entre 1988 e 2005. Rev Soc Bras Med Trop. 2008;41:602-14.

17. Ramírez JC, Cura CI, da Cruz Moreira O, Lages-Silva E, Juiz N, Velázquez E, et al. Analytical validation of qPCR methods for quantification of Trypanosoma cruzi DNA in blood samples from Chagas disease patients. J Mol Diagn. 2015;17:605-15.

18. Messenger LA, Miles MA, Bern C. Between a bug and a hard place: Trypanosoma cruzi genetic diversity and the clinical outcomes of Chagas disease. Expert Rev Anti Infect Ther. 2015;13:995-1029

19. Brenière SF, Waleckx E, Barnabé C. Over six thousand Trypanosoma cruzi strains classified into discrete typing units (DTUs): attempt at an inventory. PLoS Negl Trop Dis. 2016;10:e004792.

20. Monteiro WM, Margioto Teston AP, Gruendling AP, dos Reis D, Gomes ML, de Araújo SM, et al. Trypanosoma cruzi I and IV stocks from Brazilian Amazon are divergent in terms of biological and medical properties in mice. PLoS Negl Trop Dis. 2013;7:e2069. 